\title{
Stage I Malignant Mediastinal Germ Cell Tumor
}

National Cancer Institute

\section{Source}

National Cancer Institute. Stage I Malignant Mediastinal Germ Cell Tumor. NCI

Thesaurus. Code C146849.

Locoregional tumor, non-metastatic, complete resection. (WHO Classification of Tumors

of the Lung, Pleura, Thymus and Heart, 2015) 